Transactions of the American Fisheries Society, 1999, v.128, n.4: pp. 603-612.

http://afs.allenpress.com

http://afs.allenpress.com/archive/1548-8659/128/4/pdf/i1548-8659-128-4-603.pdf

Online ISSN: $1548-8659$

Print ISSN: 0002-8487

DOI: 10.1577/1548-8659(1999)128<0603:PHWAEO>2.0.CO;2

(C) American Fisheries Society 


\title{
Predicting How Winter Affects Energetics of Age-0 Largemouth Bass: How Do Current Models Fare?
}

\author{
Russell A. Wright, ${ }^{* 1}$ James E. Garvey, ${ }^{2}$ Aimee H. Fullerton, ${ }^{3}$ And \\ Roy A. STEIN \\ Aquatic Ecology Laboratory, Department of Zoology, \\ The Ohio State University, Columbus, Ohio 43212-1194, USA
}

\begin{abstract}
During the first winter of life, loss of energy reserves as a function of low feeding activity and scarce prey may contribute to high mortality of age-0 largemouth bass Micropterus salmoides. To explore how two current bioenergetics models predict winter energy depletion, we quantified growth and consumption by age-0 largemouth bass from Alabama, Ohio, and Wisconsin fed maintenance rations in 55-L aquaria in three simulated winters mimicking temperatures and photoperiods at low temperate latitudes (Alabama; $33^{\circ} \mathrm{N}$ ), middle latitudes (Ohio; $40^{\circ} \mathrm{N}$ ), and high temperate latitudes (Wisconsin; $46^{\circ} \mathrm{N}$ ). We compared observed growth in aquaria with that predicted by putting observed consumption into both models. During winter 1995-1996, we validated one of the models with a separate pool experiment $(5,800-\mathrm{L})$ in which age- 0 largemouth bass were fed either at $0.5 \times$ or $1.5 \times$ maintenance ration. In aquaria, energy density of the largemouth bass declined in the high- and middle- but not in the low-latitude winter. Though error was slight in the low- and middle-latitude winters for one of the models, both models underestimated growth in the high-latitude winter. To fit the model to the data, the function that estimates weight-specific resting metabolism had to be reduced by about $16 \%$. In pools, where we predicted consumption from observed growth, the model adequately predicted consumption by largemouth bass fed 1.5 $\times$ maintenance, but overestimated consumption by $0.5 \times$ maintenance individuals. Current bioenergetics models perform poorly at the cold temperatures $\left(<6^{\circ} \mathrm{C}\right)$, photoperiods, and low prey abundances typical of high-latitude lakes, likely because metabolic costs are overestimated.
\end{abstract}

For many organisms, including fishes, mortality is quite high during the first year of life. Much of this mortality occurs as individuals experience periods of unfavorable biotic or abiotic conditions (Hjort 1914; May 1974; Ludsin and DeVries 1997; Mion et al., in press). Winter severity may limit recruitment to later life stages (Lindroth 1965; Hunt 1969; Joy 1975; Oliver et al. 1979; Toneys and Coble 1979; Gutreuter and Anderson 1985; Post and Evans 1989; Ludsin and DeVries 1997) via several conceivable mechanisms, including cold intolerance (i.e., cold shock; Adams et al. 1982), predation (Joy 1975; Miranda and Hubbard 1994a; Garvey et al. 1998), and starvation (Oliver et al. 1979; Post and Evans 1989; Johnson and Evans 1990; Ludsin and DeVries 1997). Quantifying how these mechanisms ultimately influence

\footnotetext{
* Corresponding author: rwright@ acesag.auburn.edu

1 Present address: Department of Fisheries and Allied Aquacultures, Auburn University, Auburn, Alabama 36849, USA.

2 Present address: Division of Biology, Kansas State University, Manhattan, Kansas 66506-4901, USA.

${ }^{3}$ Present address: North Carolina Wildlife Resources Commission, Raleigh, North Carolina 27608-2438, USA.
}

Received November 17, 1997; accepted September 10, 1998 winter survival requires an understanding of how winter conditions affect the behavior and energetics of juvenile fish.

Overwinter starvation in many fishes derives from an energy debt caused by interactions between behavior (low feeding activity; Johnson and Charlton 1960; Sullivan 1986) and environmental conditions (low food availability; Adams et al. 1982). For largemouth bass Micropterus salmoides, the extent of first-winter mortality and its role in recruitment have been debated extensively. Some investigations have quantified high mortality of juvenile largemouth bass over winter (Gutreuter and Anderson 1985; Garvey et al. 1998) and others low mortality (Kohler et al. 1993; Garvey et al. 1998). This variable mortality may result from differences in energy depletion of largemouth bass among aquatic systems (Miranda and Hubbard 1994b; Ludsin and DeVries 1997). Further, energy depletion may interact with other mortality sources, such as predation or disease, to increase mortality (Miranda and Hubbard 1994a; Garvey et al. 1998). By modeling the energetic demands of overwintering juvenile largemouth bass, one can evaluate the relative importance of food availability and temperature regime in depleting energy reserves and, potentially, recruitment to later life stages. 
TABLE 1.-Functions and parameter values for the largemouth bass bioenergetics models governing the components of energy loss, including respiration and losses from consumption in the following relation: energy loss $=[f$ (weight) $\times f$ (temperature) $\times$ activity $]+$ wastes. The Trebitz (1991) and Hewett and Johnson (1992) models share the same weight-specific $\left(f[\right.$ weight $]=\mathrm{RA} \cdot$ weight $\left.^{\mathrm{RB}}\right)$ and temperature-dependent $\left(f[\right.$ temperature $]=e^{\mathrm{RQ}} \cdot$ temperature $)$ metabolic functions. Wastes are modeled differently: (SDA $+U) \cdot C \cdot(1-F)+(F \cdot C)$ for Hewett and Johnson (1992) and (SDA $+F+U) \cdot C$ for Trebitz (1991), where SDA is specific dynamic action, $F$ is feces, $U$ is urine, and $C$ is consumption in both models.

\begin{tabular}{lcc}
\hline & \multicolumn{2}{c}{ Parameter value } \\
\cline { 2 - 3 } \multicolumn{1}{c}{ Parameter } & Trebitz $(1991)$ & $\begin{array}{c}\text { Hewett and Johnson } \\
(1992)\end{array}$ \\
\hline Respiration & 0.0868 & 0.1163 \\
RA & -0.355 & -0.355 \\
RB & 0.0811 & 0.0811 \\
RQ & & \\
Activity multiplier & 1.0 & 1.0198 \\
$<10^{\circ} \mathrm{C}$ & $1.1 \times$ weight & \\
$>10^{\circ} \mathrm{C},<2.594 \mathrm{~g}$ & 1.0198 & 1.0198 \\
$10^{\circ} \mathrm{C},>2.594 \mathrm{~g}$ & & 1.0198 \\
Wastes & 0.142 & 0.163 \\
SDA & 0.104 & 0.104 \\
$\mathrm{~F}$ & 0.079 & 0.068 \\
$\mathrm{U}$ & & \\
\hline
\end{tabular}

A formulation of a bioenergetics model, the Wisconsin model (Hewett and Johnson 1992), has been successfully applied to the analysis of growth and food consumption by largemouth bass in the field (Rice et al. 1983; Rice and Cochran 1984). Modeling largemouth bass growth and consumption largely has been based on experiments with large juvenile and adult individuals under summer conditions (Beamish 1970; Hewett and Johnson 1992), and model validation has only occurred during these warm months (Rice and Cochran 1984). Though Trebitz (1991) modified the model for winter and Hewett and Johnson (1992) incorporated some of these changes, little is known about performance of these models under winter conditions. To predict overwinter growth and consumption by largemouth bass across their range, the model must be validated by using winter temperatures and photoperiods.

To test our ability to predict winter growth of age-0 largemouth bass throughout their natural range, we compared predictions of bioenergetics models using parameters derived either by Hewett and Johnson (1992) or Trebitz (1991) against data from a controlled, laboratory experiment at temperatures of $1-15^{\circ} \mathrm{C}$. Then we determined corrections to the models that would allow them to fit predictions for the growth of juvenile largemouth bass in winter. Finally we challenged these corrections with data from a second independent experiment.

\section{Methods}

Models.-The bioenergetics models that we compare are based on the mass balance equation (units are energy equivalents)

$$
\begin{aligned}
\text { growth }= & \text { consumption } \\
& -(\text { respiration }+ \text { specific dynamic action } \\
& + \text { urine }+ \text { feces })
\end{aligned}
$$

In this relation, respiration depends on both temperature and weight, whereas specific dynamic action, urine, and feces depend on consumption.

As mentioned previously, two versions of this model exist for largemouth bass. Trebitz (1991) adapted parameters of the Wisconsin model for largemouth bass, incorporating data for small fish and cold temperatures. Because simulations overestimated weight loss over winter, Trebitz constrained weight loss to no more than $10 \%$ of body weight per day, arguing that the model overestimates energy requirements at winter temperatures. Hewett and Johnson (1992) modified changes made by Trebitz (1991) so that the revised model would better fit summer respiration and therefore growth while still accounting for winter conditions (B. L. Johnson, U.S. Geological Survey, personal communication). Bioenergetics models formulated by Trebitz (1991) and Hewett and Johnson (1992) differ in functional relationships and parameter values used (Table 1).

Aquarium experiment.-The aquarium experiment was designed to test size and temperature 
dependence of mortality, consumption, and energy depletion for juvenile largemouth bass from stocks originating across the species' native latitudinal range. For this paper we limit our analysis to a subset of the largemouth bass that survived to the end of the experiment, were provided food, and for which energy density was determined. Although the experiments were originally designed for factorial analysis (i.e., blocks of replicated individuals), we later chose to compare model predictions and actual growth for individual largemouth bass.

Age-0 largemouth bass were captured by either pulsed-DC electrofishing or shoreline seining from four locations distributed across most of the native latitudinal range of the species: Trilby Lake, northern Wisconsin $\left(46^{\circ} \mathrm{N}\right)$; Knox Reservoir and the Hebron State Fish Hatchery, Ohio $\left(40^{\circ} \mathrm{N}\right)$; and farm ponds on the Auburn University Experiment Station, Alabama $\left(33^{\circ} \mathrm{N}\right)$ in fall 1994. Largemouth bass from the Hebron State Fish Hatchery are derived from stocks in St. Mary's Lake, Ohio. All largemouth bass were held in the laboratory and fed fathead minnows Pimephales promelas for 6 weeks at $15-20^{\circ} \mathrm{C}$ before experiments began.

Largemouth bass were divided into average total length $(\mathrm{mm})$ categories (Alabama: small $=74$, large $=132$; Ohio-Knox: small $=67$, large $=110$, extra large $=161$; Ohio-hatchery: small $=74$; Wisconsin: small $=80$, large $=107$ ) and placed in $55-\mathrm{L}$ aquaria that were divided into three equalsized compartments. Three largemouth bass $(N=$ 9 largemouth bass per treatment) of a known sizestock combination were placed into each compartment after they had been marked individually with a combination of latex dye injections in the caudal peduncle and dorsal spine clips. Largemouth bass from each size-stock combination, except Ohio hatchery largemouth bass, were subjected to winter regimes of both photoperiod and water temperature corresponding to winters near the northern edge of the range of largemouth bass (northern Wisconsin), in the middle of the range (Ohio), and the southern portion of the range (Alabama). Ohio hatchery largemouth bass were exposed only to Ohio winter conditions. Temperature regimes (Figure 1) were determined from winter temperature profiles for northern Wisconsin Lakes (Long Term Ecological Research [LTER] program for North Temperate Lakes, 1992-1994; J. J. Magnuson, University of Wisconsin, personal communication), central Ohio reservoirs (Garvey et al. 1998), and farm ponds on the campus of Auburn University (Ludsin 1994). The experiment began
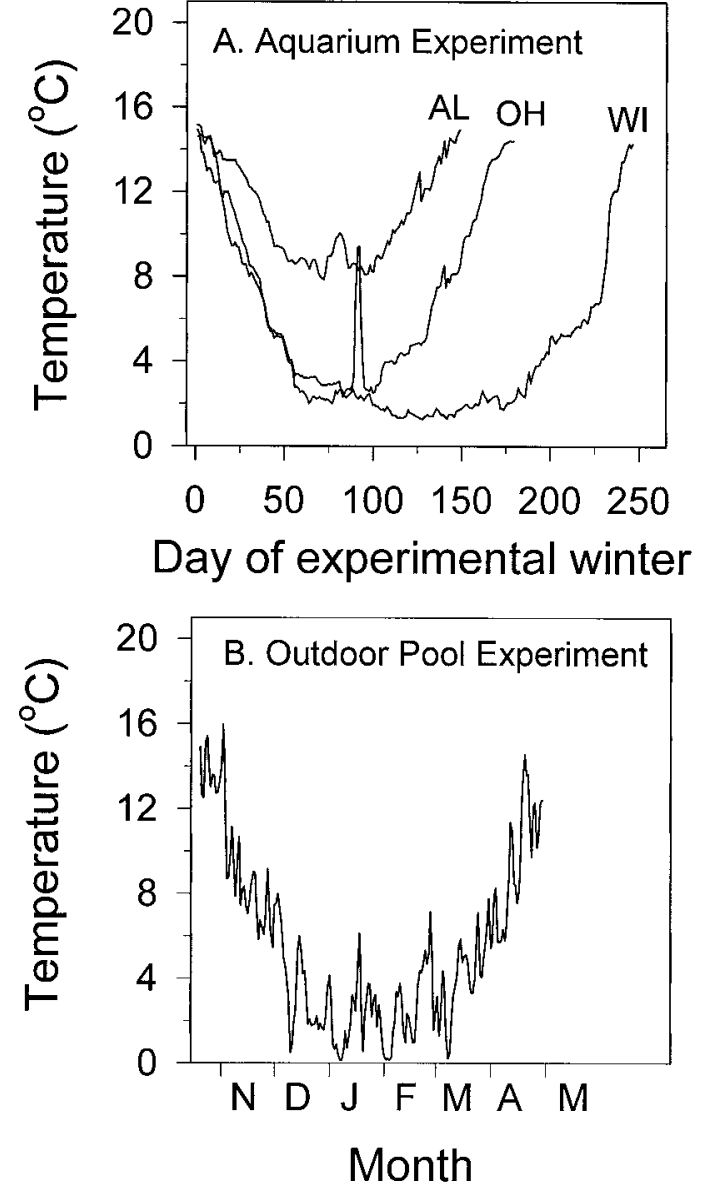

FIGURE 1.-Daily average temperatures recorded from (A) the aquarium experiment and (B) the outdoor pool experiment. Temperature regimes for the aquarium experiment were derived from water temperatures taken in Alabama (AL), Ohio (OH), and Wisconsin (WI). The rapid increase in temperature in the Ohio winter regime on days 90-92 was due to a temporary failure of the cooling system.

on 3 January with all fish at $15^{\circ} \mathrm{C}$ and on a fall photoperiod and continued to 6 June, 27 June, and 5 September to simulate Alabama, Ohio, and Wisconsin winters respectively.

Largemouth bass were fed a ration of live fish equal to maintenance ration as determined from the Hewett and Johnson (1992) bioenergetics model. To provide small enough prey, largemouth bass up to $100 \mathrm{~mm}$ total length were fed guppies Poecilia reticulata. Largemouth bass longer than 100 $\mathrm{mm}$ long were fed fathead minnows. Captures by individual largemouth bass were recorded for 10 min beginning immediately after prey were added to aquaria. If all prey were not consumed during 
this period, largemouth bass were allowed access to prey for $24 \mathrm{~h}$; uneaten prey were then removed. If consumption could not be attributed to a particular largemouth bass (which occurred in about $33 \%$ of our observations when temperatures were cold and fish were feeding infrequently), we assigned missing prey at random to largemouth bass in the compartment. The exact consumption by each largemouth bass would provide the most precise comparisons of the models to observed growth, but we believe the error generated by this random assignment of prey to be unbiased, although this method certainly increased the variability of our results.

Growth.-Energy density of largemouth bass, fathead minnows, and guppies was determined by bomb calorimetry (Rand et al. 1994). For largemouth bass and fathead minnows, we determined caloric density of homogenates of individual fish, stratified across available sizes, at the outset and the end of each winter. For large fish, two estimates were averaged for each individual. Too small to analyze individually, several guppies were combined to create a sample. Because bomb calorimetry requires killing the fish, initial energy density for largemouth bass used in the experiment was estimated by taking subsamples from each stock of individuals that were not used in the experiment. Fish used for initial energy density estimates were acclimated to experimental conditions exactly as those used for the experiment. Energy density at the end of winter was determined for each bass used in the analysis. We used linear interpolation to estimate energy density of largemouth bass throughout the experiment. Because body sizes differed among stocks, it was inappropriate to compare growth responses as a function of origin in analyses. Therefore, we combined responses across all stocks for analyses. Percent change in both wet weight and energy density-[(final - initial)/initial] $\times 100$ - was calculated for individuals for which energy density was quantified. Changes in both growth and energy density as functions of wet weight (the covariate) and winter were analyzed with analysis of covariance (ANCOVA). Statistical software was used for analyses (SAS Institute 1985).

Model comparisons to aquarium data.-We simulated daily growth of individual largemouth bass, incorporating observed consumption and temperature, using the Trebitz (1991) and Hewett and Johnson (1992) models. For each treatment, the mean percent difference between observed and predicted growth was $t$-tested against the null hypothesis of zero percent difference. A twodimensional Kolmogorov-Smirnov (2DKS) test (Garvey et al. 1997) was used to test for a nonrandom relationship between body size and model fit for each simulated winter.

The amount of correction of respiration needed to adequately predict weight change over the course of the experiment was estimated for each winter duration by multiplying respiration by proportions ranging from 1.05 to 0.75 , which alters total metabolism in the models. For each value of respiration, the growth of each largemouth bass was simulated and the residuals from actual growth were calculated. A polynomial regression was then fitted to the relationship between the correction of respiration and the summed absolute value of residual error. Absolute value, rather than sum-ofsquares minimization, was calculated because the residual error lacked normality (Press et al. 1992). The value of the change in respiration at the minimum of this polynomial function (where the value of the first derivative equaled 0 ) provided an estimate of the correction needed to best fit observed growth.

1995-1996 pool experiments.-To further test the energetic models with and without corrected respiration from the aquarium experiment, we conducted a second independent experiment in 5,800L outdoor pools (see Garvey et al. 1998 for complete methods). This experiment provided estimates of consumption and growth for age-0 largemouth bass operating at a spatial scale larger than 55-L aquaria.

Largemouth bass were seined from Hebron State Fish Hatchery ponds on 5 October 1995, held for 1 week in outdoor pools, then measured and individually marked with combinations of fin clips and subcutaneous latex dye marks. Each experimental pool was stocked with four small (mean TL, $91.9 \mathrm{~mm}$; mean weight, $8.7 \mathrm{~g}$ ), four medium $(103.6 \mathrm{~mm} ; 12.7 \mathrm{~g})$, and two large $(131.9 \mathrm{~mm}$; $30.3 \mathrm{~g})$ largemouth bass. On 30 October, each largemouth bass was weighed (nearest $0.1 \mathrm{~g}$ ) and measured (nearest $1 \mathrm{~mm}$ ). Largemouth bass not used in the experiment were frozen for energy density analysis.

Juvenile largemouth bass were fed fathead minnows once per week at one of two ration levels (three replicate pools per ration): $0.5 \times$ or $1.5 \times$ maintenance.. We determined ration levels using the Hewett and Johnson (1992) version of the bioenergetics model and a temperature regime from a prior winter experiment in our outdoor pools. We assumed that all fathead minnows would be eaten 
within 1 week. As water temperatures declined in the fall, we observed that prey fish had accumulated uneaten in the high-ration tanks. Therefore, to be able to control food availability and estimate consumption, we removed all uneaten prey on day 76; thereafter, we removed all unconsumed prey weekly.

All fathead minnows added to pools were measured (nearest $1 \mathrm{~mm}$ ) and weighed (nearest $0.1 \mathrm{~g}$ ). Any that were not eaten were measured and weighed. Consumption per pool was the difference between weight of fathead minnows removed and weight of those stocked. Individual largemouth bass weights and lengths were determined on days 76, 127, and 182. At the end of the experiment, surviving largemouth bass were frozen for energy density measurements. As in aquaria, energy density was determined from a sample of largemouth bass at the beginning and end of the experiment. Linear interpolation was used to estimate energy density throughout the experiment. Temperatures were recorded about every $2 \mathrm{~h}$ with a data logger in two pools (Figure 1).

Model comparison to pool experiment.-We tested model performance against pool data only for the model that provided the best fit to aquarium Data. Consumption by largemouth bass in each pool was predicted from changes in energy density and growth of individual bass and average daily pool temperatures. The estimates for each largemouth bass in a pool were summed, and the total for the pool was compared to the observed consumption for each period (days 76, 127, 182). Summing consumption across all bass was necessary because individual consumption rates could not be determined. By combining consumption by largemouth bass across a range of sizes, our estimates and therefore errors were most highly influenced by the growth of fish in the large sizeclass. Large individuals have greater potential consumption rates than small fish. The effect of ration on differences between model-derived and observed estimates of consumption was determined with repeated-measures analysis of variance (ANOVA).

\section{Results}

\section{Aquarium Experiment}

Survival differed among largemouth bass from Alabama, Ohio, and Wisconsin. Though largemouth bass from Ohio and Wisconsin survived all three simulated winters similarly, $80 \%$ and $100 \%$ of Alabama largemouth bass in Ohio and Wiscon-

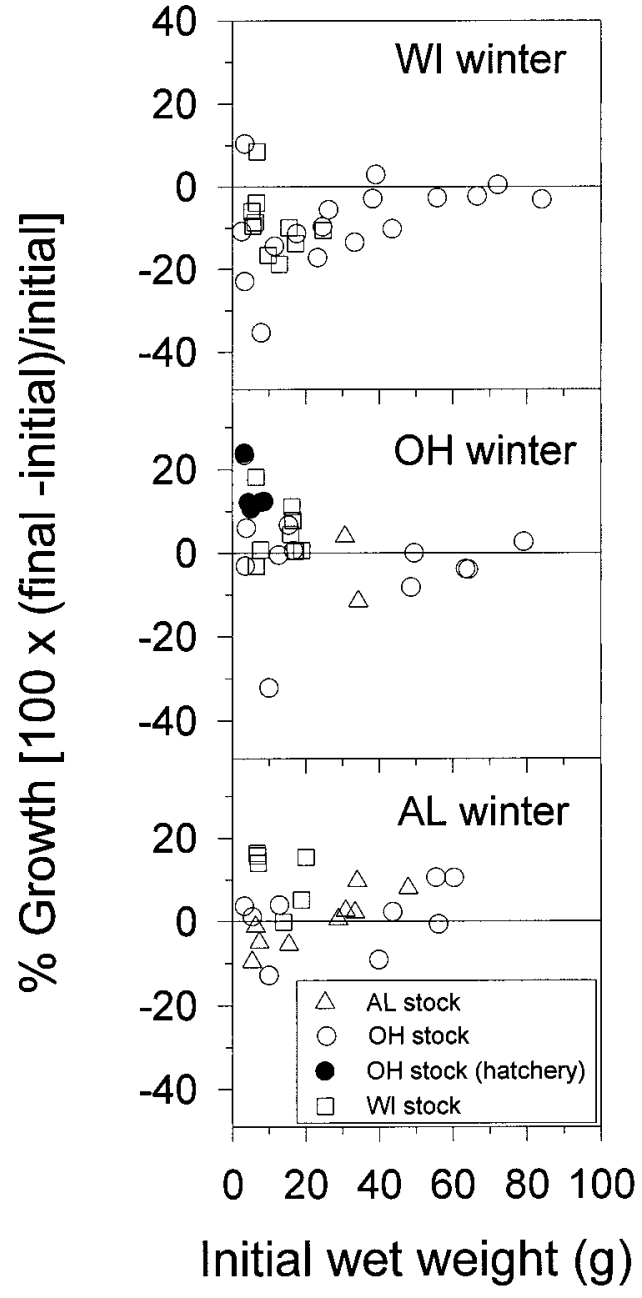

FIGURE 2.-Percent growth (change in wet weight) of largemouth bass from the aquarium experiment in which Alabama (AL; $N=25)$, Ohio $(\mathrm{OH} ; N=27)$, and Wisconsin (WI; $N=27$ ) winters were simulated.

sin winters died, respectively (A. H. Fullerton, unpublished data). Largemouth bass grew more in the Alabama and Ohio than in the Wisconsin winters (ANCOVA: $N=79$; winter, $F=13.7$, df $=$ 2, 73, $P=0.0001$; weight, $F=0.02$, df $=1,73$, $P=0.90$; winter $\times$ weight, $F=3.4$, df $=2,73$, $P=0.04$; Figure 2$)$. Average $( \pm 1 \mathrm{SE})$ percent changes in wet weight for the individuals used in this analysis were $3.7 \pm 3.3,3.4 \pm 4.3$, and -8.8 \pm 3.6 in the Alabama, Ohio, and Wisconsin winters, respectively. Change in energy density over winter was positively related to initial wet weight across winters (ANCOVA: weight, $F=8.8$, df = $1,73, P=0.004$; Figure 3 ). Energy density declined more in the Wisconsin and Ohio winters 


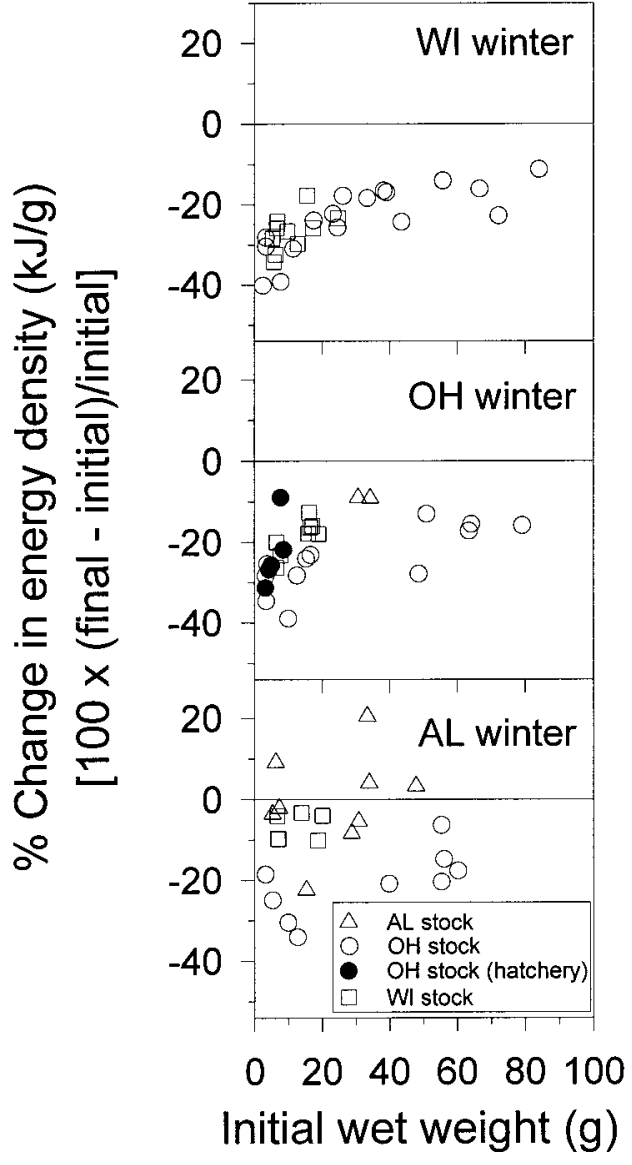

FIGURE 3.-Percent change in energy density $(\mathrm{kJ} / \mathrm{g}$ wet weight) of largemouth bass from the aquarium experiment in which Alabama (AL; $N=25)$, Ohio $(\mathrm{OH}$; $N=27$ ), and Wisconsin (WI; $N=27$ ) winters were simulated.

than the Alabama winter (ANCOVA: winter, $F=$ 13.7, df $=2,73, P=0.0001$; winter $\times$ weight, $F$ $=1.4$, df $=2,73, P=0.26$; Figure 3).

\section{Comparison to Bioenergetics Models Predictions}

When compared across winter regimes, the published models more closely predicted observed growth in the Alabama and Ohio winters than in the Wisconsin winter (Figure 4). The percent error produced by the Trebitz model did not differ from zero in the Alabama and Ohio winters ( $t$-tests: $N$ = 25-27; $P>0.14)$. The Hewett and Johnson (1992) model produced significant errors for the Ohio and Alabama winters ( $t$-tests: $N=25-27$; $P<0.04)$. Both the models proposed by Hewett and Johnson (1992) and Trebitz (1991) underestimated the growth achieved by largemouth bass during the longest winter exposure ( $t$-test: $\mathrm{N}=27$; $P<0.0001)$. Although variation in the ability of the models to predict growth appears higher for small individuals across all winters, this pattern was statistically significant only for the Hewett and Johnson comparison to fish from the Wisconsin winter (2DKS test: $N=27 ; P=0.0002$ ).

We limited optimization to deviation from the Trebitz model. Optimizing respiration costs to achieve a best fit to the observed growth gave proportional changes in resting metabolism of 1.008, 0.966 , and 0.843 for Alabama, Ohio, and Wisconsin winters, respectively.

\section{Consumption Estimation}

Because the Trebitz (1991) model produced a better fit to growth data from the aquarium experiment, it was tested against data from the pool experiment. Results of the modified and unmodified (respiration reduced by 3.4\%) Trebitz (1991) models differed only slightly (Figure 5). Hence, we restricted analysis to the unmodified model. Though the model adequately estimated consumption at the $1.5 \times$ maintenance ration, the model overestimated the level of consumption required for observed growth at $0.5 \times$ maintenance ration (repeated-measures ANOVA: ration, $F=462.7$, df $=1,2, P=0.002$; Figure 5). This overestimation appeared to be most pronounced in fall as water temperatures declined (repeated-measures ANOVA: time, $F=5.6$, df $=2,2, P=0.06$; Figure 5).

\section{Discussion}

\section{Growth}

Because body sizes often differed among individuals from Alabama, Ohio, and Wisconsin, direct comparisons were often impossible. However, among the subsets of similarly sized individuals, energetic responses to winter conditions produced similar mean results. However, responses were more variable for small than for larger individuals. Poor survival of Alabama largemouth bass prevented us from assessing their energetic responses in the intermediate-length (Ohio) and long (Wisconsin) winters. For surviving largemouth bass in Alabama and Ohio winters, wet weight did not change, as predicted for fish feeding at maintenance ration. In contrast, all largemouth bass subjected to the Wisconsin winter lost wet weight. Though wet weight changes were nominal in the Ohio winter, energy density declined. Hence, during intermediate and long winters, fed age-0 large- 


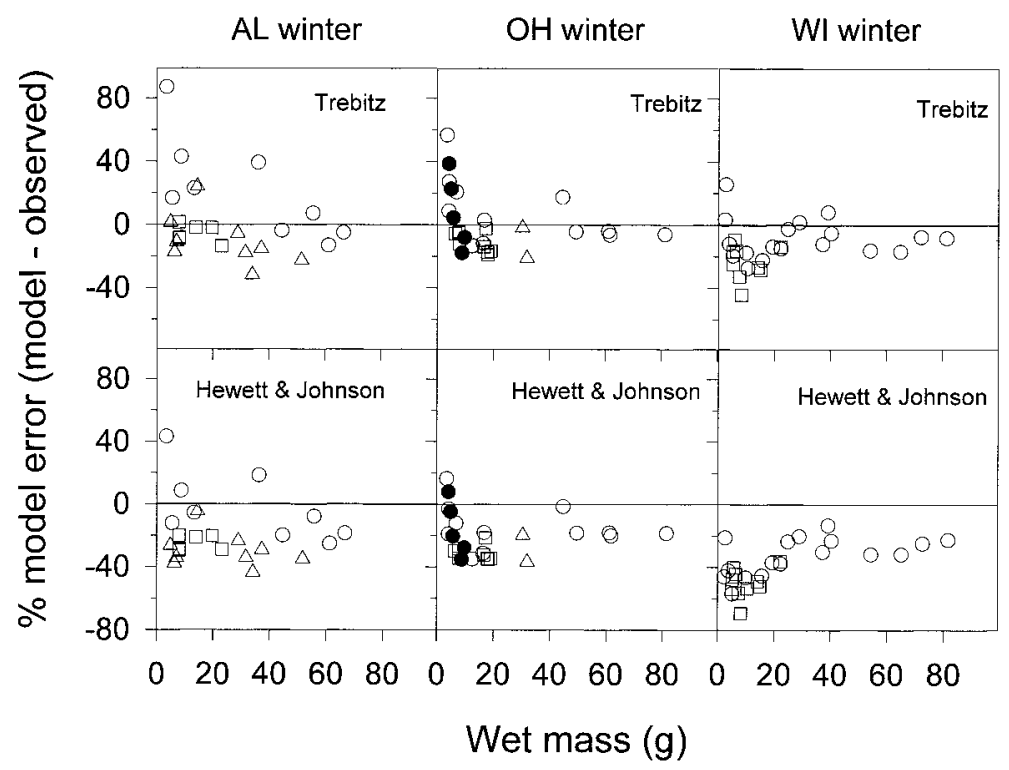

FIGURE 4.-Percent error in final wet weight of individual largemouth bass produced by the Trebitz and the Hewett and Johnson models for Alabama (AL; $N=25)$, Ohio $(\mathrm{OH} ; N=27)$, and Wisconsin (WI; $N=27)$ winter conditions. Fish stock symbols are those of Figures 2 and 3.

mouth bass suffered an energy debt even while given a maintenance ration.

At temperatures below $6^{\circ} \mathrm{C}$, largemouth bass feed infrequently or stop feeding completely (Lemons and Crawshaw 1981; Garvey et al. 1998), and feeding frequency declined below this temperature in our aquarium experiment (this study; A.H.F., unpublished data), likely preventing largemouth bass from consuming sufficient food to offset their metabolic costs. In the Wisconsin and Ohio winters, the proportion of days spent at these low temperatures caused a net energetic loss. Other "warmwater" fishes such as smallmouth bass $\mathrm{Mi}$ cropterus dolomieu stop feeding at cold temperatures (Oliver et al. 1979; Shuter et al. 1980). Perhaps, reduced feeding activity and increased torpor are adaptive mechanisms to reduce the energetic costs of feeding during a time when food is typically scarce (Crawshaw 1984; Evans 1984; Sullivan 1986). Though reduced feeding may be adaptive during most winters, longer winters at higher latitudes may increase the energetic cost of overwintering when food is abundant (likely a rare occurrence). Hence, the northern limit of largemouth bass may be set when energy reserves in the fall are insufficient to offset the costs of long winters, regardless of food availability during that time.

\section{Models}

Because this study and previous work (Oliver et al. 1979; Post and Evans 1989; Johnson and
Evans 1990; Miranda and Hubbard 1994b; Ludsin and DeVries 1997) demonstrate that winter conditions can reduce the energy reserves of age- 0 fish and potentially their survival, we must evaluate whether current bioenergetics models accurately predict winter growth and energy depletion. From our experiments, we conclude that the parameters characterizing metabolism in these models are inadequate in describing observed growth. Though largemouth bass did lose energy during intermediate and long winters, both models (Trebitz 1991; Hewett and Johnson 1992) overestimated winter metabolic costs, though the amount of error differed between the two. Below, we discuss these models and their underlying differences.

In the multiple-winter aquarium experiment, the Hewett and Johnson (1992) model overestimated overwintering cost by more than $20 \%$ during all simulated winters. Conversely, the Trebitz (1991) model adequately predicted growth in both Alabama and Ohio winters but not in the long-duration Wisconsin winter, where it overestimated wet weight loss by about $20 \%$. To allow the model to fit observed winter data, we had to reduce the resting metabolism by $16 \%$, likely because actual respiration costs were lower than originally predicted. Although confounded by differences in form of the functions used to estimate metabolism, it is clear that adjustments to respiration estimates from the parameters in the Hewett and Johnson (1992) 


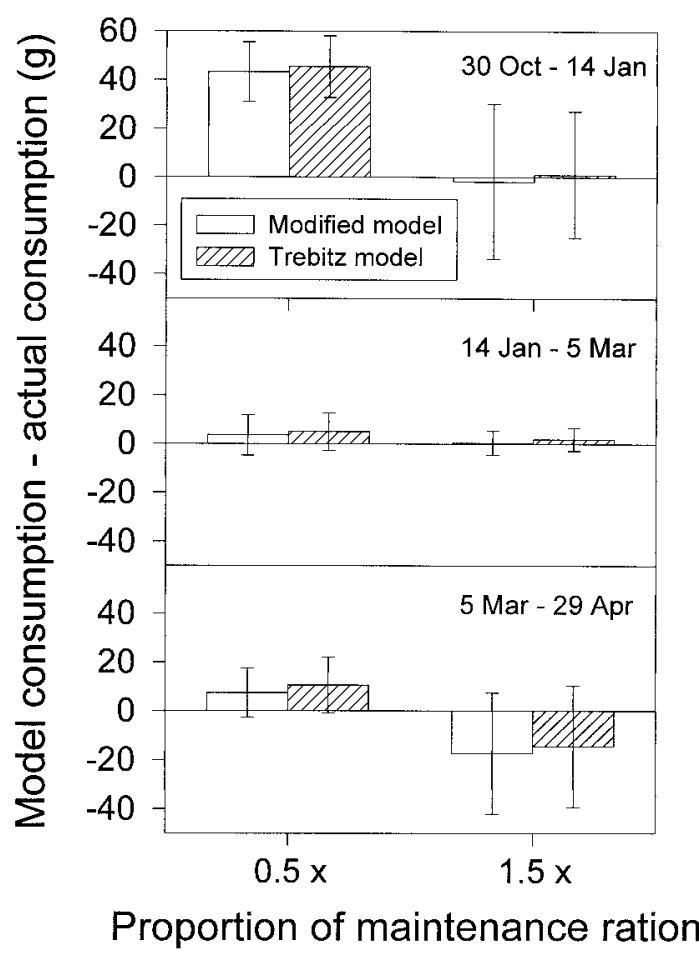

FiguRE 5.-Mean difference ( $\pm 1 \mathrm{SE})$ between predicted and observed feeding rates (wet weight of prey consumed per period) of largemouth bass in the outdoor pool experiment $(N=3$ pools per feeding level). Predictions from the modified model derive from simulations in which the intercept for weight-specific respiration was reduced by $3.4 \%$.

model would be larger than needed for Trebitz's (1991) formulation.

The notion that bioenergetics approaches fail to predict winter growth of largemouth bass is not new. Historically, investigators assumed that largemouth bass do not feed below $10^{\circ} \mathrm{C}$, and such low temperatures often prevail during a large proportion of the winter (Markus 1932; Johnson and Charlton 1960). This assumption has led to large overestimates of weight loss and energy depletion (Adams et al. 1982; Sullivan 1986; Carline 1987). To remedy these overestimates, Adams et al. (1982) concluded that largemouth bass likely seek relatively warm areas (above $10^{\circ} \mathrm{C}$ ) of high prey availability to offset winter costs. Conversely, Carline (1987) simply concluded that metabolic parameters were inaccurate at low temperatures. In our view, largemouth bass feed actively at lower temperatures (between $10^{\circ}$ and $6^{\circ} \mathrm{C}$, Garvey et al. 1998) and likely reduce their metabolic costs through acclimation.
Reducing metabolism during winter might be common among fishes that experience long periods of inactivity and low food availability. Through winter acclimation, pumpkinseeds Lepomis gibbosus reduce their resting metabolic rates relative to summer values, likely as an adaptive response to offset a low net energy gain when food is scarce (Evans 1984). Such acclimation is not a response to declining winter temperature but rather to seasonal photoperiod (Evans 1984; also see Fry 1964). Changes in metabolic rate, other physiological processes, or behavior as responses to seasonal photoperiod are important in many fishes (e.g., green sunfish Lepomis cyanellus: Gross et al. 1965; Atlantic salmon Salmo salar: Withey and Saunders 1973; Eurasian perch Perca fluviatilis: Karås 1990). In our experimental winters, the latitude-specific winter photoperiods included in our design potentially reduced the resting metabolism of age- 0 largemouth bass relative to that predicted at cold temperatures for individuals acclimated to summer photoperiods.

In our independent test of the original and modified Trebitz (1991) models in pools, we predicted consumption from observed growth, then compared these estimates to observed consumption. Prey abundance influenced model performance. At high ration, predicted and observed consumption matched quite closely during winter, suggesting that the response of resting metabolism to temperature was similar to model predictions. Conversely, at low ration, the model overestimated consumption relative to that observed in pools, especially during fall. As with winter conditions, low feeding rates may induce torpor or extremely low activity in largemouth bass (Sullivan 1986). Hence, largemouth bass receiving a low ration in pools may have reduced their metabolic costs or activity further than that predicted by either model, lowering potential energetic costs. This ability to shift between high and low average respiration rates as a function of prey density would have strong adaptive significance for juvenile largemouth bass living in a variable feeding environment, especially during winter when prey availability varies dramatically (Adams et al. 1982). Because we were unable to separate consumption by large and small largemouth bass in the pool experiment, we could not test the interaction of ration and body size on model outcome. Results from the aquarium experiment show a high individual variation in response to winter duration at small body size. Any variation in consumption by 
small largemouth bass was certainly masked by the feeding rates of larger individuals in the pools.

This study was not designed to produce the data necessary to derive changes in model parameters necessary to simulate winter energetics. More carefully controlled experiments from which components of the metabolic costs could be estimated independently are needed to derive appropriate changes in bioenergetic models for low temperatures and low food consumption. Experiments designed to separate activity and basal metabolic changes at low temperatures, particularly around $6^{\circ} \mathrm{C}$, and at reduced food availability will be critical for determining if changes in metabolism represent shifts in metabolic pathways (i.e., different enzyme systems) or simply a reduction in routine activity. It seems that alternative approaches are possible for simulating growth and consumption by largemouth bass across seasons and latitudes. Either separate models could be constructed for winter conditions and low food, or functions in the current models could be modified with greater flexibility to account for these same conditions.

Our experiments suggest that current bioenergetics models perform poorly at prolonged temperatures below $6^{\circ} \mathrm{C}$ in combination with highlatitude photoperiods and reduced rations. Certainly, metabolic rates decline with declining temperature (Beamish 1970). However, seasondependent, acclimatory reductions in resting metabolism, combined with the potential impact of ration size, may further reduce metabolic costs of overwintering. Though this physiological flexibility confounds model predictions, it does make adaptive sense. In winters that are short or in environments with dense prey, age-0 largemouth bass should possess the evolutionary flexibility to feed actively and grow over winter. Conversely, in winters that are long with scarce prey, it should be advantageous if largemouth bass possessed the option (as we have quantified here) to reduce their metabolism, eliminate their active feeding, and minimize their energetic costs.

\section{Acknowledgments}

We thank Kristen Ferry, Bridey Thompson, Heather McCann, Rick Ginsberg, Stephanie Micucci, and Tom Stahl for their help in the field and laboratory. We also thank Jim Stafford and his staff at the Hebron State Fish Hatchery for their generous support as well as Auburn University and the Wisconsin Department of Natural Resources for providing largemouth bass. We gratefully acknowledge Mark Kershner's insightful review.
This research was funded by National Science Foundation grant DEB 9407859 to R.A.S. and Federal Aid in Sport Fish Restoration Project F-69-P, administered jointly by the U.S. Fish and Wildlife Service and the Ohio Division of Wildlife. A University PostDoctoral Fellowship and a Presidential Fellowship from The Ohio State University supported R.A.W. and J.E.G., respectively, during part of this work.

\section{References}

Adams, S. M., R. B. McLean, and J. A. Parrotta. 1982. Energy partitioning in largemouth bass under conditions of seasonally fluctuating prey availability. Transactions of the American Fisheries Society 111: $549-558$.

Beamish, F. W. H. 1970. Oxygen consumption of largemouth bass, Micropterus salmoides, in relation to swimming speed and temperature. Canadian Journal of Zoology 48:1221-1228.

Carline, R. F. 1987. Simplified method based on bioenergetics modeling to estimate food consumption by largemouth bass and northern pike. Transactions of the American Fisheries Society 116:224-231.

Cichra, C. E., W. H. Neill, and R. L. Noble. 1982. Differential resistance of the northern and Florida largemouth bass to cold shock. Proceedings of the Annual Conference Southeastern Association of Fish and Wildlife Agencies 34(1980):19-24.

Crawshaw, L. I. 1984. Low temperature dormancy in fish. American Journal of Physiology 246:479-486.

Evans, D. O. 1984. Temperature independence of the annual cycle of standard metabolism in the pumpkinseed. Transactions of the American Fisheries Society 113:494-512.

Fry, F. E. J. 1964. Animals in aquatic environments: fishes. Pages 715-725 in D. B. Dill, E. F. Adolph, and C. G. Wilber, editors, Handbook of physiology. Section 4: adaptation to the environment. American Physiological Society, Washington, D.C.

Garvey, J. E., E. A. Marschall, and R. A. Wright. 1998. From star charts to stoneflies: detecting relationships in continuous bivariate data. Ecology 79:442447.

Garvey, J. E., R. A. Wright, and R. A. Stein. 1998. Overwinter growth, and survival of age-0 largemouth bass: revisiting the role of body size. Canadian Journal of Fisheries and Aquatic Sciences 55:2414-2424.

Gross, W. L., E. W. Roelofs, and P. O. Fromm. 1965. Influence of photoperiod on growth of green sunfish Lepomis cyanellus. Journal of the Fisheries Research Board of Canada 22:1379-1386.

Gutreuter, S. J., and R. O. Anderson. 1985. Importance of body size to the recruitment process in largemouth bass. Transactions of the American Fisheries Society 114:317-327.

Hewett, S. W., and B. L. Johnson. 1992. Fish bioenergetics model 2. An upgrade of a generalized bioenergetics model of fish growth for microcomput- 
ers. University of Wisconsin, Sea Grant Institute, Technical Report WAS-SG-92-250, Madison.

Hjort, J. 1914. Fluctuations in the great fisheries of northern Europe viewed in light of biological research. Rapports et Proces-Verbaux des Reunions Conseil International pour 1'Exploration de la Mer 20:1-228.

Hunt, R. L. 1969. Overwinter survival of wild fingerling brook trout in Lawrence Creek, Wisconsin. Journal of the Fisheries Research Board of Canada 26: 1473-1483.

Johnson, M. G., and W. H. Charlton. 1960. Some effects of temperature on the metabolism and activity of the largemouth bass, Micropterus salmoides, Lacepede. Progressive Fish-Culturist 22:155-163.

Johnson, T. B., and D. O. Evans. 1990. Size-dependent winter mortality of young-of-the-year white perch: climate warming and invasion of the Laurentian Great Lakes. Transactions of the American Fisheries Society 119:301-313.

Joy, E. T., Jr. 1975. The walleye, Stizostedion vitreum (Mitchill), population and sport fishery of the Big Eau Pleine, a fluctuating, central-Wisconsin reservoir. Master's thesis. University of Wisconsin, Stevens Point.

Karås, P. 1990. Seasonal changes in growth and standard metabolic rate of juvenile perch, Perca fluviatilis L. Journal of Fish Biology 37:913-920.

Kohler, C. C., R. J. Sheehan, and J. J. Sweatman. 1993. Largemouth bass hatching success and first-winter survival in two Illinois reservoirs. North American Journal of Fisheries Management 13:125-133.

Lemons, D. E., and L. I. Crawshaw. 1981. The role of acclimation temperature in the induction of torpidity in the largemouth bass. Acta Universitatis Carolinae Biologica 1979:353-356.

Lindroth, A. 1965. First winter mortality of Atlantic salmon parr in the hatchery. Canadian Fish Culturist $36: 23-26$.

Ludsin, S. A. 1994. Understanding first-year survival of a freshwater piscivore: the interdependency of life-history stages. Master's thesis. Auburn University, Auburn, Alabama.

Ludsin, S. A., and D. R. DeVries. 1997. First-year recruitment of largemouth bass: the interdependency of early life stages. Ecological Applications 7: $1024-1038$.

Markus, H. C. 1932. The extent to which temperature changes influence food consumption in largemouth bass (Huro floridana). Transactions of the American Fisheries Society 62:202-210.

May, R. C. 1974. Larval mortality in marine fishes and the critical period concept. The early life history of fishes. Springer-Verlag, New York.

Mion, J. B., R. A. Stein, and E. A. Marschall. 1998. River discharge drives differential survival of larval walleye. Ecological Applications 8:88-103.

Miranda, L. E., and W. D. Hubbard. 1994a. Winter sur- vival of age-0 largemouth bass relative to size, predators and shelter. North American Journal of Fisheries Management 14:790-796.

Miranda, L. E., and W. D. Hubbard. 1994b. Lengthdependent winter survival and lipid composition of age-0 largemouth bass in Bay Springs Reservoir, Mississippi. Transactions of the American Fisheries Society 123:80-87.

Oliver, J. D., G. F. Holeton, and K. E. Chua. 1979. Overwinter mortality of fingerling smallmouth bass in relation to size, relative energy stores, and environmental temperature. Transactions of American Fisheries Society 108:130-136.

Philipp, D. P. 1992. Stocking largemouth bass outside its native range. Transactions of the American Fisheries Society 121:688-691.

Post, J. R., and D. O. Evans. 1989. Size-dependent overwinter mortality of young-of-year yellow perch (Perca flavescens): laboratory, in situ enclosure, and field experiments. Canadian Journal of Fisheries and Aquatic Sciences 46:1958-1968.

Press, W. H., S. A. Teukolsky, W. T. Vetterling, and B. P. Flannery. 1992. Numerical recipes in C: the art of scientific computing. Cambridge University Press, New York.

Rand, P. S., B. F. Lantry, R. O'Gorman, R. W. Owens, and D. J. Stewart. 1994. Energy density and size of pelagic prey fishes in Lake Ontario, 1978-1990: implications for salmonine energetics. Transactions of the American Fisheries Society 123:519-534.

Rice, J. A., J. E. Breck, S. M. Bartell, and J. F. Kitchell. 1983. Evaluating the constraints of temperature, activity and consumption on growth of largemouth bass. Environmental Biology of Fishes 9:263-275.

Rice, J. A., and P. A. Cochran. 1984. Independent evaluation of a bioenergetics model for largemouth bass. Ecology 65:732-739.

SAS Institute. 1985. SAS user's guide: statistics, version 5, edition. SAS Institute, Cary, North Carolina.

Shuter, B. J., J. A. MacLean, F. E. J. Fry, and H. A. Regier. 1980. Stochastic simulation of temperature effects on first-year survival of smallmouth bass. Transactions of the American Fisheries Society 109: $1-34$.

Sullivan, K. M. 1986. Physiology of feeding and starvation tolerance in overwintering freshwater fishes. Environmental Biology of Fishes 7:259-268.

Toneys, M. L., and D. W. Coble. 1979. Size-related, first winter mortality of freshwater fishes. Transactions of the American Fisheries Society 108:415-419.

Trebitz, A. S. 1991. Timing of spawning in largemouth bass: implications of an individual-based model. Ecological Modelling 59:203-227.

Withey, K. G., and R. L. Saunders. 1973. Effect of a reciprocal photoperiod regime on standard rate of oxygen consumption of postsmolt Atlantic salmon (Salmo salar). Journal of the Fisheries Research Board of Canada 30:1898-1900. 